\title{
HOMENAGENS A UM JOVEN ESCRIPTOR BRASILEIRO (1)
}

No Jornal do Brasil tem publicado varios estudos sobre questões economicas e financeiras, o Dr. Braz de Sousa Arruda, joven, mas já illustre escriptor paulista, filho do Dr. João Braz de Oliveira Arruda, emerito cathedratico da Faculdade de Direito de S. Paulo.

Os trabalhos do Dr. Braz de Sousa Arruda mereceram não só attenção como applauso dos especialistas na materia, nacionaes e estrangeiros. Entre outros, o grande economista francez Charles Gide, professor de Economia Social na Faculdade de Direito de Paris e Escola Nacional de Ponts et Chaussés, autor de tratados celebres sobre o assumpto, redactor da excellente Revue d'Économie Politique, dirigiu ao Dr. Braz de Souza Arruda significativa carta de que a imprensa deu noticia.

Recentemente, o nosso patricio foi objecto de honrosas demonstrações de apreço por parte dos Srs. Alcibiades Roldán e Estanislau Zeballos. O primeiro, notabilidade chilena, e o segundo, argentina.

São as constantes dos seguintes documentos:

"Santiago, 3 de enero de 1919.

Señor Profesor Doctor Braz de Sousa Arruda. - S. Paulo. - Brasil. Señor Profesor:

He leido el estudio de Ud. titulado "Eleições", publicado en los números 18 y 21 de noviembre ultimo del "Jornal do Brasil", de esa ciudad que ha tenido la bondad de remitirme.

(1) Artigo publicado no Jornal do Brasil de 3 de Fevereiro de 1919 pelo insigne poeta e eminente jurisconsulto Sr. Conde de Affonso Celso. 
Sus observaciones acerca de la necessidad de depurar los procedimientos clectorales de los vicios de que adoleceu, a fin de que sea praticado el gobierno del pueblo por el pueblo en forma leal y sincera, segun el ideal de nuestras organizaciones democraticas, me han parecido mui justas y atinadas. Participo en absoluto de sus opiniones en orden al rol que corre ponde a los partidos politicos en el juego de las instituciones representativas, particularmente en lo que mira al funccionamiento regular de aquelles procedimientos, y en este sentido doi, como Ud., la mayor importancia a la organizacion de tales partidos.

Esperando que su interessante trabajo habrá de contribuir a la consecucion del noble objecto que Ud. ha tenido en vista al escribirlo, me suscribo de Ud., Señor Profesor, con la mayor consideracion.

A. S. S. y colega,

Alcibiades Roldán."

"Buenos Aires, Diciembre 28|18.

Illmo. Snr. Dr. Braz de Sousa Arruda, Faculdade de Direito de S. Paulo. - Brasil.

Eminente colega. - Tuve la honra de recibir los notables articulos de Ud. ("Jornal do Bracil"), sobre la regeneración politica de su pais por medio de la adopcion de un sistema electoral adecuado.

Su erudicion es completa y su orientacion excelente. Estoy de acuerdo en general con Ud.

Como Ud. mismo lo observa, no basta la obra sabia del legislador. Es necessario que los ciudadanos tengan inteligencia y voluntad para votar con independencia y sabiduria. El Brasil, como todos los pueblos de America, debe esperar su redencion politica mas de la educacion que de las leyes. En la Republica Argentina se ha adelantado mucho camino en los ultimos años por medio del voto secreto y obligatorio.

El sitio principal es del secreto, pues la obligacion ha sido desoida por un alto votado secretamente $y$ lo han hecho con singular acierto, seleccionando candidatos, de modo que triunfaron siempre los mas preparados $y$ prestigiosos.

Ha quedado evidenciado asi el adelantado cultural progreivo de nue tra masa electoral.

Acaban de tener lugar varias elecciones estaduales (Entre Rios, Cordoba y Salto) en provincias argentinas de perfeccion de la mayor importancia. Elas se acercan de la perfeccion democratica por la correccion de las autoridades, por lo entusiasmo de los partidos y por su reciproca tolerancia y respecto.

Los partidos que ocupaban los gobiernos de esas provincias y el de la nacion, han sido denotados. Ud. debe estudar, eminente colega, esas elecciones que aportan argumentos vivientes y decisivos a su noble propaganda.

El eminente brasileño Oliveira Lima ha contemplado eses espectaculos y visitado Cordoba y Entre Rios. Pronto estará en S. Paulo y podrá dar dados a Ud. Al agradecer a Ud. el honor con que me ha favorecido me es grato felicitarlo por su trabajo y desearle feliz año nuevo.

E. S. Zeballos." 
A carta do Dr. Zeballos encerra informações e conceitos dignos da maior ponderação, sobretudo quando breve se vae proceder em nossa terra á eleição presidencial. Oxalá se aproximasse ella da Argentina, pela perfeição democratica, correcção das autoridades, enthusiasmo dos partidos e sua reciproca tolerancia e respeito.

A. C.

\section{CARTA DO PRINCIPE DOS CONSTITUCIONALISTAS AMERICANOS, O PRECLARO BLACK}

\section{Fourteenth Street.}

Washington D. C., 6th, November, 1919.

My esteemed and illustrious confrere.

It is with very great interest and pleasure that $I$ have read the: admirable "Dissertaçôes", which you were so good as to send me. I thank you for giving me the privilege of reading them, as also for your very generous praise of my own humble works in the field of contitutional lawpraise which, I fear, is for above my small merits. In return you will not refuse to accept my sincere compliment; on the industry, the learning, the erudition, and the logic which your "Dissertações" display.

The constitutional law of the great countries of South America hx; always possessed great interest for me, and therefore I am interested in learnnig from your writings that the movement of governmental power in Brasil is centrifugal. Here in the United States it is so strongly centripetal - and increases in that direction - that many fear the autonomy of the States will be destroyed entirely.

I shall take the liberty of sending you a copy of a journal, "The Constitutional Review", of which $I$ am the editor, which $I$ beg you to accept with my compliments, and in the hope that you may find something in it that you will care to read.

It would give me much pleasure to receive a letter from you from time to time, and if you will so far honor me I will endeavor to reply not unworthily.

I must also ask your indulgence and pardon for writing to you in English.

For although I can read the noble and beautiful language of Brasil, I have not learned to speak it or write it. But it is evident that you are master of the English language, and therefore $I$ shall not offend you in using it.

Receive, Excellentissimo Senhor Doutor, the assurance of my high consideration and my thanks and believe me

Faithfully yours

Henry Campbell Black. 


\title{
CARTA DO INSIGNE INTERNACIONALISTA HOLLANDEZ JITTA
}

\author{
Monsieur le Professeur Braz de Sousa Arruda.
}

Mon cher collègue.

S. Paulo, Bra:il.

Je me permets de vous écrire en français parce que je n'oserais pas me servir de votre langue. J'ai eu l'honneur de recevoir un exemplaire "Das dissertações apresentadas á Faculdade de Direito de São Paulo", et je vous remercie vivement de votre hommage de sympathie, auquel je suis trè; sensible.

J'ai lu avec interêt les travaux qui $m$ on parlé "dos submarinos de guerra", "dos extrangeiros divorciados a vinculo em seu paiz", et enfin de la que tion de savoir si "a Uniäo póde impor aos Estados um alistamento eleitoral para as eleições locaes".

Veuillez me croire votre très dévoué

D. Josephus Jitta.

Rio, 20 de Outubro de 1919.

Exmo. Collega Snr. Dr. Braz Arruda.

Tenho a grande satisfacção de lhe apresentar as minhas sinceras felicitações, pelo brilho com que vae honrando o nome do eminente jurisconsulto seu digno Pae e meu prezado amigo, a quem já tanto devem as letras juridicas.

Antes da conferencia e dos artigo; que me remetteu ultimamente, e que só em Agosto é que recebi devolvidos da Bahia, tinham me chegado ás mãos alguns trabalhos seus, denunciadores de robusto talento a serviço de bem orientada applicação.

Deixei então de os agradecer, por ignorar o endereço.

Soube que ultimamente concorreu a uma cadeira na Faculdade de São Paulo; estimo que tenha obtido o reconhecimento de seu alto merito. Se possivel, faça-me o obsequio de remetter as theses que apresentou.

Offerecendo-lhe os meus prestimos, peço-lhe o obsequio de me considerar sempre seu collega admirador e amigo

Eduardo Espinola.

De uma carta do Dr. D. José Leon Suarez, Professor da Universidade de Buenos Aires, ao Dr. João Arruda:

....... "Não posso deixar de felicital-o pela digna prolongação intellectual que the faz o seu filho, Dr. Braz de Sousa Arruda; li o seu di. curso em prol da candidatura do colosso Ruy Barbo a $e$ as tres monographias publicadas este anno sobre direito internacional publico, int. privado e constitucional; são trabalhos de indiscutivel merito.

José Leon Suarez. 
Rio, 12 de Setembro de 1919.

Meu prezado collega Snr. Dr. Braz de Sousa Arruda.

Gratissimo me confesso pela offerta tão gentil das suas tão elegantes dissertações sobre o direito das gentes, o direito internacional privado e o direito constitucional, que li com muito prazer e não menor proveito.

Saudações do amigo admirador aff.

J. X. Carvalho de Mendonça.

Meu distincto Exmo. e muito prezado confrade.

Após uma verdadeira odysséa postal, recebi ha dias e concluida tenho a leitura de trabalhos juridicos da sua lavra, que teva a bondosa e penhorante amabilidade de me offertar e fazer presentes.

Li-os e por elles só tenho a, juntamente com os meus melhores agradecimentos, significar-lhe todo o meu regosijo e sincero apreço.

Não era exempto de difficuldades o interessante problema de Direito, que o meu Exmo. confrade se propoz versar, o que em laborio:o exito, mais vem valorisar o seu esforço e os creditos daquella classe jurispericional, que tantos e tão abalisados cultores regista nesse grande e querido paiz, o Brasil, e á qual óra se addiciona um tão sympathico, valio:o e erudito cooperador.

Receba, Exmo., as minhas mais affectuosas saudações e queira dispor do collega admirador e amigo

J. Lobo d'Avila Lima.

(Lente da Universidade de Coimbra).

Sobre a traducção da "Actualidade Maquiavel":

Distincto Senhor.

Recebi a carta e a revista e agradeço muito especialmente a horira que me fez,

Como vós em vos o paiz, eu no meu, trabalho para approximar os espiritos.

Conhecendo-nos nos estimaremos e se afastarão todas as possibilidades de disputas desagradaveis.

Felizmente a época que vem será de paz, de patria. E nossos paizes viverão tranquillos e felizes, em cordial amizade.

Especial homenagem e saudações.

Juan Agustin Garcia.

(Reitor da Universidade de Buenos Aires).

\section{CARTA DO EMINENTE LITERATO, INSIGNE JURISCONSULTO E DISTINCTO DIPLOMATA OLIVEIRA LIMA}

Ao distincto patricio e amigo Snr. Dr. Braz de Sousa Arruda, cumprimenta affectuosamente, $M$. de Oliveira Lima e penhorado agradece o offerecimento das suas theses de concurso para a cadeira da Faculdade de Direito de S. Paulo, muito tendo apreciado as mesmas e felicitando-o por ellas. Com especial agrado, interesse e proveito leu a que se refere ao uso dos submarinos de guerra com relação aos principios do direito internacional. 


\title{
DO GRANDE INTERNACIONALISTA CLOVIS BEVILAQUA
}

Meu distincto collega.

Agradeço-lhe a remessa de suas tres dissertações juridicas, onde vejo confirmados os seus creditos de espirito valoroso e conhecedor da difficil sciencia do Direito. Agradeço-lhe tambem a delicadeza e a generosidade com que me trata, ainda quando dissente das minhas opinióes.

Felicito-o pelos valiosos trabalhos que estão a indicar um mestre.

Rio, 4 de Set. 919.

Clovis Bevilaqua.

\section{DO GRANDE LITERATO E EMINENTE MESTRE DE DIREITO SNR. CONDE DE AFFONSO CELSO}

\author{
Rio, 1. ${ }^{\circ}$ de Setembro de 1919.
}

Ao Prezado Confrade, Collega e Amigo Snr. Dr. Braz de Soura Arruda, cumprimenta affectuosamente o abaixo assignado, agradecendo a remessa do; bellos trabalhos de S. S. sobre Direito das Gentes, D. Inst. Privado e D. Constitucional, mais um valioso documento da operosidade $e$ competencia do digno collega.

Queira elle acceitar, com estes agradecimentos, as congratulações do muito seu

Conde de Affonso Celso.

\section{DO EMINENTE PROFESSOR DA FACULDADE DE DIREITO DE S. PAULO E ILLUSTRE MINISTRO DAS RELAÇÕES EXTERIORES, SR. DR. AZEVEDO MARQUES}

Ao Exmo. Snr. Dr. Braz de Soura Arruda.

Agradeço a remessa dos seus trabalhos publicados em jornaes e folhetos que leio com satisfacção; e felicito-o pelo amor ao e`tudo do Direito, com a mesma applicação revelada quando foi meu discipulo.

Aperto de mão do

$$
\text { Coll. }^{\mathrm{a}} \mathrm{Am}^{\circ}{ }^{\mathrm{O}} \mathrm{Obr}^{\circ}
$$

Azevedo Marques.

Exmo. Snr. Dr. João Arruda.

Buenos Aire:, Diciembre 8 de 1919.

S. Paulo (Brasil).

Tengo el honor de acusarle recibo a su folleto "Acção de Enriquecimento", que tuve V. E. la bondad de enviarme y que he leido con mucho interes y provecho, habiendome ilutrado con las sabias doctrinas que V. E. desarrolla.

Aprovecho esta oportunidad para agradecerle desde aqui todas las atenciones que V. E. me dispensó asi como la ilu tre congregación de la Facultad de Derecho de esa culta e importantissima capital.

Por medio del Snr. Dr. Eugenio Lefévre, del Ministerio de Agricultura de San Paulo, le vo y a enviar un ejemplar encuadernado de mis conferencias el año passado en su gran pais. Debido a multitud de inconvenientes, no 
han salido antes. Empiezo a enviar a todos los amigos que me dispensaron sus amabilidades y a fin de no olvidar alguns ruego a $V$. E. se sirva hecerme enviar una lista que me sirva de memorandum, o encarguele al Dr. Braz, su señor hijo, a quien tengo que escribirle, que tenga la bondad de apuntarme esos nombres.

Recibirá tambien V. E. el nombramiento de Socio Correspondonte del Ateneo Hispano-Americano, el que 'por un error no le ha sido mandado antes.

No puedo menos que felicitar a V. E. por la digna prolongación intelectual que le hace su hijo, el Dr. Braz de Sousa Arruda. He leido su discurso en pró de la candidatura del coloso Ruy Barbosa y las tres monografias, publicadas este año sobre derecho internacional público, privado y constitucional; son trabajos de indiscutible mérito.

Con el mayor reconocimiento lo saluda amo. colega y S. S.

José LEón SuÁrez.

\section{CARTA DO EXCELSO INTERNACIONALISTA ARGENTINO,} DR. J. LEÓN SUÁREZ

Exmo. Snr. Dr. João Arruda. - Ilustre colega:

Soy mui senible a las deferencias que $V$. S. me ha dispensado y muy especialmente al obsequio de sus fundamentales libros "Do Casamento" y "Decreto n. 2.044, de 31 de Dezembro de 1908".

He ojeado el primero y me será muy grato leerlo en B. Aires, lo mismo que a la segunda obra que trata de un assunto de Derecho Comercial tan importante y fundamental en nuestra época como es la letra de cambio y sus diversas evoluciones y consequencias.

He tenido mucho gusto en leer en "O Jornal do Brasil" de 21 de Abril ppdo. el articulo que tanto me interesa, escrito por su hijo, sobre "Los intereses económicos en las relaciones internacionales". Este articulo lo recortaré y anotaré en mi carpeta respectiva de la cátedra de Derecho Internacional y Comercial.

Ruego a V. S. quiera ser interprete ante el Dr. Braz de Sousa Arruda de mi agradecimiento por el envio de sus "Conferencias Patrioticas" y hacerle llegar el folleto que le acompaño.

No teniendo a mano sino mi ultima publicación sobre "Las Embajadas" se la remito con el volúmen $1^{\circ}$ y único publicado, de la Academia de Derecho.

Lo saluda con su más alta consideración 